\title{
Years of life lost due to lower extremity injury in association with dementia, and care need: a 6-year follow-up population- based study using a multi-state approach among German elderly
}

Ying Zhou ${ }^{1,2}$, Hein Putter ${ }^{3}$ and Gabriele Doblhammer ${ }^{1,2,4^{*}}$

\begin{abstract}
Background: Dementia and care need are challenging aging populations worldwide. Lower extremity injury (LEI) in the elderly makes matters worse. Using a multi-state approach, we express the effect of LEl on dementia, care need, and mortality in terms of remaining life expectancy at age 75 (rLE) and years of life lost (YLL).

Methods: A population-based random sample of beneficiaries aged 75-95 years was drawn from the largest public health insurer in Germany in 2004 and followed until 2010 (N 62,103; Mean Age \pm SD $81.5 \pm 4.8$ years; Female $71.2 \%$ ). We defined a five-state model (Healthy, Dementia, Care, Dementia \& Care, Dead), and calculated transition-specific hazard ratios of LEl using Cox regression. The transition probabilities as well as the YLL due to LEl were estimated.

Results: LEl significantly increased the risk for each transition, with a maximum risk for the transition from Healthy to Care (HR: 1.70, 95 \% Cl: 1.63-1.77) and a minimum risk for the transition from Care to Dead (HR: 1.16, 95 \% Cl: 1.10-1.22). If the elderly had LEl-history, their age-specific mortality was generally higher and their probabilities of transient states peaked at younger ages. At age 75, initially dementia-free and care-independent elderly experiencing LEl lost about 2 years of life, of which more than $90 \%$ were life years free of dementia or care need. Dementia patients lost about one and a half year, more than $60 \%$ were free of long-term care need.

Conclusions: LEl not only casts a large health burden on care need, but is also associated with cognitive decline and shortened rLE. LEl plus dementia extend the relative life time in need of care, despite generally shortening rLE. Using the composite measure YLL may help to better convey these results to the elderly, families, and health professionals. This may strengthen preventive measures as well as improve timely and rehabilitative treatment of LEl, not only in cognitive and physically intact elderly.
\end{abstract}

Keywords: Long-term care, Mortality, Cohort analysis, Dementia, Multi-state analysis

\footnotetext{
* Correspondence: doblhammer@rostockerzentrum.de

${ }^{1}$ Institute for Sociology and Demography, University of Rostock, Ulmenstrasse

69, 18057 Rostock, Germany

${ }^{2}$ Rostock Center for the Study of Demographic Change, Konrad-Zuse-Str. 1,

18057 Rostock, Germany

Full list of author information is available at the end of the article
} 


\section{Background}

As the world's population ages, age-dependent disorders are of great concern. Dementia, a key age-dependent disorder, dramatically contributes to disability and dependency, thereby challenging the health care system substantially [1].

Geriatric trauma, another age-related disorder, is also drawing more attention in public health [2]. With age, physiological reserve capability declines, physiologic reaction to injury degenerates, and age-related multimorbidity and polypharmacy worsen disability and mortality after injuries [3, 4]. Traumatic injuries also pose a challenge to health care [2], and rank as the fifth leading causes of death in elderly [3].

The lower extremities, covering the hip, thigh, knee, lower leg, ankle and foot, are one of the most likely region of the body for traumatic injuries in old adults $[5,6]$. We focus on lower extremity injury (LEI), which includes not only hip fractures but also other types of fractures and fall-induced LEI, all of which increase the risk of mortality and deleterious disability and long-term care [7, 8]. LEI is also related with limitation of mobility and social participation $[9,10]$.

Numerous studies demonstrate an association between geriatric LEI and care need [7, 10-13]. LEI dramatically contributes to functional decline and increased dependency for basic and instrumental activities of daily living (ADL) $[7,10,11]$. In particular, dementia patients suffering the LEI are more likely to get poor functional outcomes and long-term care need $[10,14]$. In turn, those living in long-term care institutions have also substantially increased rates of falls and fractures [12].

Previous research suggests an association between geriatric LEI and dementia [15-17]. Dementia increases the risk of falling and LEI disproportionately $[18,19]$. In turn, LEI might lead to depression and delirium, as well as the restricted physical and social activity, which contributes to a cognitive decline and dementia onset [16, 20-24].

A bunch of studies reveal that geriatric LEI increases mortality considerably [8, 10, 25-29]. The mortality following LEI is even higher in people with dementia than people without dementia $[25,30,31]$. Moreover, the impairment in basic ADL (BADL) prior to LEI is also significantly associated with increased risk of mortality following LEI [32].

But most of the previous studies analyzed the associations separately. It lacks research to evaluate the effects of LEI on functional and survival outcomes during the aging process holistically. The aging process covers two major functional declines, namely physical decline and cognitive decline [33]. Dementia can be regarded as a later state of cognitive impairment [33], whereas the impairment in the BADL and the consequent care need can be regarded as a later state of physical impairment.

A holistic analysis of LEI effects in the aging is valuable because all forms of dementia, care need and premature mortality add a health burden on a society with an aging population, and also because LEI and dementia as well as mobility and cognitive dysfunction may interact and in particular aggravate one another, leading to a profound combined effect on care need and mortality $[33,34]$. Moreover, the investigation of both survival and functioning outcomes simultaneously has also been recommended in the geriatric research such as LEI and successful aging $[35,36]$.

Hence, we used a multi-state model to simultaneously evaluate the effect of LEI on the endpoints dementia, care need, and death with the focus on the transitions from one state to another over age [37-39]. As successfully applied in previous studies, multi-state models help quantify how risk factors at the individual level alter life expectancy at the population level [40]. The compound measures derived from multi-state models, such as remaining life expectancy (rLE) and years of life lost (YLL), are highly intuitive to the public and to health professionals and help quantify the health burden and make intervention choices [40].

Additional methodological shortcomings in prior research include sample size and short-term follow up in longitudinal studies [26, 27]. Previous studies have commonly been based only in hospital settings, or used cohorts consisting only of voluntary participants, both of which excluded nursing home residents.

Therefore, we aimed to use a large nationally representative sample of Germans living in private households and in nursing homes with a 6-year follow-up to: (1) simultaneously investigate the association between LEI and dementia, care need, as well as death; (2) explore the transition probabilities of getting dementia, care need, and dying from various initial states, stratified by LEI; (3) estimate to what extent LEI influences rLE, as well as rLE with dementia and care need; and (4) quantify the consequences of LEI in terms of YLL.

\section{Methods}

\section{Sample and study design}

We used claims data from the largest public health insurer in Germany (AOK), which covered about onethird of the German population. A national $2.2 \%$ random sample of AOK beneficiaries aged 50 years and older, regardless of whether they went to the doctor, was drawn in the first quarter of 2004. We used the data in 2004 to classify the initial states, and followed the 62,103 individuals in our sample who were between 75 and 95 years of age from 2005 to 2010. In this age range, usually various transitions to dementia, care need and 
death occur. Medical and care need data were available from both the inpatient and the outpatient sectors for each person for each quarter, except that the data of care need from 2004 to 2006 were documented only once a year. The dataset supporting the conclusions of this article is not publicly available. Data access was legally approved by the "Wissenschaftliches Institut der Ortskrankenkassen" (WIdO). The study is based on anonymised administrative claims data that never involved patients directly. Individual patients cannot be identified and the analyses presented do not affect patients whose anonymized records were used.

\section{Variables of interest}

We used ICD-10 to identify dementia (Dementia: G30, G31.0, G31.82, G23.1, F00, F01, F02, F03, and F05.1). To account for false positive diagnoses we developed a validation procedure. First, only diagnoses indicated as "verified" by a medical doctor were included from outpatient services, while from inpatient services only the discharge and secondary diagnoses were considered. Second, only those diagnoses with a second occurrence in the same quarter by different types of physicians or over time were considered. The only exception was when a patient died immediately after a dementia diagnosis in the same quarter; all of these cases were considered valid dementia cases [41].

We defined care need as receiving benefits from the statutory long-term care insurance in Germany. Such insurance includes cover for long-term care at home or in an institution, and is statutory and compulsory for all citizens in Germany [42]. The long-term care benefits are available for all insured persons, irrespective of age or wealth. The Medical Advisory Service of the Statutory Health Insurance Funds assesses whether there is need of care. Based on the German law regarding long-term care insurance in the study period (2004-2010), care need in our study refers to a minimum of assistance for at least 90 min per day, with more than 45 min per day attributable to basic care in the BADLs such as washing, eating or dressing. This implies that dementia patients with intact ADLs do not receive benefits and, thus, in our study are not coded as being in need of care.

Our exposure of interest was LEI, namely injuries to the hip and thigh, the knee and lower leg as well as the ankle and foot [6]. We used ICD to identify LEI (S70 S99 and its related T section of the ICD codes, see details in Additional file 1: Table S1).

\section{Model}

We applied a multi-state model to assess the risk of LEI for the eight possible transitions between the four transient states Healthy, Dementia, Care, Dementia \& Care, and the only absorbing state Dead (Fig. 1). The state Healthy contains all individuals without a dementia diagnosis and without care need. Those with an incident or prevalent dementia diagnosis but without care need are contained in the state Dementia; those with incident or prevalent care need but without a dementia diagnosis are in the state Care. Insurants who have both a dementia diagnosis and are in need of care are included in the state Dementia \& Care. The model does not consider recovery from dementia and from care need, which is reflected in Fig. 1 by the absence of the respective transitions. At present dementia cannot be treated and mild cognitive impairment, which can revert, has a separate ICD-10 number and is not part of our study. Recovery from care need is excluded because of the very small number of cases with a transition from care need to no care need. Individual persons may experience multiple transitions across different states during the follow-up period; as recovery is not possible, there are no multiple transitions of the same type.

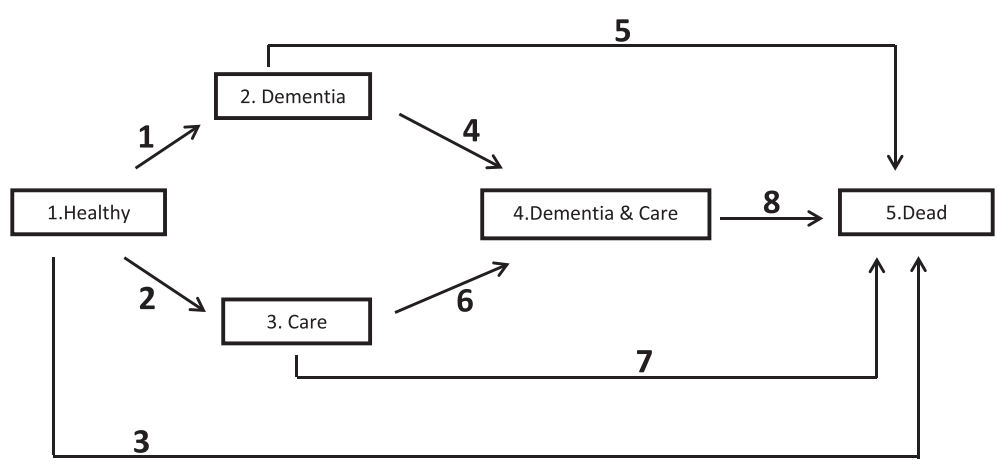

Fig. 1 Multi-state model of the stages of healthy, dementia, care and dead. The boxes represent five states: (1) Healthy refers to no dementia, no care need. (2) Dementia includes incident and prevalent dementia, but without care need. (3) Care includes incident and prevalent care need, but without dementia (4) Dementia \& Care refers to both dementia and care need. (5) Dead refers to a dead state, the only absorbing stage in our model. The other four states are transient states. The arrows represent the eight transitions from the ORIGIN STATE to the DESTINATION STATE 
We estimated stratified Cox proportional hazard models, with LEI as a time-dependent and transitionspecific explanatory variable, sex as a stratification factor, and age as process time, under consideration of right censoring and left truncation [43]. Right censoring was identified as changing to another health insurer, reaching age 95 during the follow-up, and staying in one of the transient states on December 31, 2010. For each individual the date of birth was given; the date of death was recorded if he/she died during the study time; the date of the dementia and LEI diagnoses were also given by the quarter of the year which also applied to the variable care need between 2007 and 2010. Age on January 1, 2005 was used for the left truncation. In addition, when estimating transition hazards, for each transition, age of entry into the origin state of that transition was used as left truncation. We treated dementia, care need, and LEI as "ever"-variables, which have the value one the first time they are recorded in the data and thereafter; otherwise they have the value zero. Since care need before 2007 was only recorded annually, it was assumed to occur in the middle of the year if the individual survived to the end of that year; for individuals who died in that year it was placed in the middle of the survival period. In addition, given our quarter-based data, we assumed that all the transitions and LEI occurred in the midpoint of each quarter with the following exceptions: if an individual experienced multiple transitions and/or LEI in the same quarter of the year, then dementia, care need and LEI occurred before death; dementia occurred before care need; LEI occurred before care need and dementia. We conducted sensitivity analyses under different assumptions of the ordering which did not affect our results. We also checked the proportional hazard assumptions in the Cox models which were generally fulfilled.

We obtained the hazard ratio and $95 \%$ confidence interval of LEI for each transition hazard in our multistate model. The transition probability was defined as $P_{h j}(s, t)=P(X(t)=j \mid X(s)=h)$, which denoted the transition probability from state $\mathrm{h}$ to state $\mathrm{j}$ in the time (age) interval $(\mathrm{s}, \mathrm{t}]$ [44], namely the probability that the subject is in state $j$ at age $t$, given that he/she is in state $h$ at age s. Estimates of the transition probabilities were obtained from the estimated transition hazards using the AalenJohansen formula $[43,45]$. We estimated and plotted the age-specific transition probabilities of men and women by LEI in the age range between 75 and 95, starting at an individual's $75^{\text {th }}$ birthday with various initial states. Furthermore, we estimated the state-specific rLE for a 75 -year-old individual by calculating the state-specific expected duration of stay for a 75-year-old individual with various initial states. Moreover, we compared the state-specific rLE under LEI exposure and under no-LEI exposure by using the composite measure YLL due to LEI. We restricted the state-specific rLE from age 75 to 95 according to the age range of our study population. We bootstrapped $95 \%$ confidence intervals for the state-specific rLEI and YLL by performing a thousand replications to resample the sample data with replacement. We used the "mstate" package in R 3.0 to perform the multi-state analysis [44].

\section{Results}

In the first quarter of 2005 our sample comprised 62,103 insured persons (mean age \pm standard deviation: $81.5 \pm$ 4.8 years; $71.2 \%$ female); of these $74 \%(N=45,758)$ were in the state Healthy, $5 \%(N=2,888)$ in the state Dementia, $13 \%(N=7,835)$ in the state Care, and $9 \%$ $(N=5,622)$ in the state Dementia \& Care. During the follow up, 25,730 persons died, 1,538 persons changed to other health insurance companies, and 6,651 persons reached ages over 95.

The first part of Table 1 (Col I-VI) shows the number of persons at risk of transitioning in each ORIGIN STATE (Col I) as well as the number of transitions from ORIGIN STATES to DESTINITION STATES during follow up (Col II to VI). Between 2005 and 2010, 45,758 individuals were at risk of transitioning from the state Healthy (Col I). Of these, 7,699 (17 \%) experienced a transition to the state Dementia, 12,302 (27 \%) to Care, 5,446 (12\%) to Dead, and 20,311 (44 \%) remained in state Healthy through the end of the study or the time point of right censoring $(\mathrm{Col} \mathrm{II} \sim \mathrm{VI})$. Of the 10,587 individuals in the risk population of the state Dementia between 2005 and 2010 (Col I), 6,977 individuals changed to the state Dementia \& Care (Col IV), 1,349 to the state Dead (Col V), and 2,261 had no change (Col VI). The second part of Table 1 shows the number of persons with LEI and the proportion of LEI in each ORIGIN STATE (Col VII VIII). 10,690 individuals had LEIhistory in the state Healthy (Table 1, Col VII). In the states Dementia and Care about $30 \%$ individuals had LEI-history (30.5\% and $31.9 \%$ respectively), in the state Dementia \& Care it was 41.7 \% (Col VIII). Additional file 2: Table S2 details this information by 5 -year age groups.

LEI accelerated health deterioration and significantly increased the risk of each transition (Table 2). LEI increased the risk of almost all transitions from the states Healthy or Dementia by about $50 \%$ or more, whereas LEI increased the risk of all other transitions to a smaller extent (by 16-28\%). Among all eight transitions the effect of LEI was largest for the risk of a transition from Healthy to Care: it was $70 \%$ higher for those with LEI than for those without LEI (HR: 1.70, 95\%CI: 1.63-1.77). The two sexes did not differ significantly in their effect sizes (results not shown). 
Table 1 Numbers and percentages of transitions and exposure of interest (LEI)

\begin{tabular}{|c|c|c|c|c|c|c|c|c|}
\hline \multirow{3}{*}{ Origin State } & \multirow{3}{*}{$\begin{array}{l}\text { I } \\
\text { Risk set (persons) }\end{array}$} & 11 & III & IV & V & \multirow{3}{*}{$\begin{array}{l}\text { VI } \\
\text { No change }\end{array}$} & \multirow{3}{*}{$\begin{array}{l}\text { VII } \\
N \text { of } \\
\text { LEl }\end{array}$} & \multirow{3}{*}{$\begin{array}{l}\text { VIII } \\
\% \text { of }\left.L E\right|^{c}\end{array}$} \\
\hline & & \multicolumn{4}{|c|}{ Destination state } & & & \\
\hline & & 2. Dementia & 3. Care & 4. Dementia \& care & 5. Dead & & & \\
\hline \multirow[t]{2}{*}{ 1. Healthy } & 45,758 & 7699 & 12,302 & & 5446 & 20,311 & 10,690 & 23.4 \\
\hline & $100 \%$ & $17 \%$ & $27 \%$ & & $12 \%$ & $44 \%$ & & \\
\hline \multirow[t]{2}{*}{ 2. Dementia } & 10,587 & & & 6977 & 1349 & 2261 & 3228 & 30.5 \\
\hline & $100 \%$ & & & $66 \%$ & $13 \%$ & $21 \%$ & & \\
\hline \multirow[t]{2}{*}{ 3. Care } & 20,137 & & & 5734 & 7705 & 6698 & 6422 & 31.9 \\
\hline & $100 \%$ & & & $28 \%$ & $38 \%$ & $33 \%$ & & \\
\hline \multirow[t]{2}{*}{ 4. Dementia \& Care } & 18,333 & & & & 11,230 & 7103 & 7637 & 41.7 \\
\hline & $100 \%$ & & & & $61 \%$ & $39 \%$ & & \\
\hline
\end{tabular}

anumbers of individuals who were under the risk of the transitions from "ORIGIN STATE" to "DESTINATION STATE" on January 01,2005 or during the follow up. ${ }^{\text {b }}$ numbers and percentage of individuals who entered or began with the particular ORIGIN STATE and stayed in that state until the end of the study or until the time point of right censoring. ${ }^{c}$ proportion with LEl in the ORIGIN STATE

Figure 2 shows the age-specific estimated probabilities of the transitions from the four initial states Healthy $\left(1^{\text {st }}\right.$ row), Dementia ( $2^{\text {nd }}$ row), Care ( $3^{\text {rd }}$ row) and Dementia $\mathcal{E}$ Care ( $4^{\text {th }}$ row), stratified by the presence of LEI and sex. For example, Fig. 2, $1^{\text {st }}$ row illustrates the transition probabilities for a synthetic cohort initiating in the state Healthy on the 75th birthday. At exact age 85, the probability of a woman without LEI to be in state Dementia was $5.7 \%$, in state Care $9.5 \%$, in state Dementia $\mathcal{E}$ Care $10.6 \%$, in state Dead $32.7 \%$, and to remain in the state Healthy $41.4 \%$. For most transitions, the age-specific probability for both sexes of entering a deteriorating state was larger for those with LEI than for those without LEI. Regarding the transitions to transient states, for both sexes the transition probabilities peaked at younger ages for those with LEI than for those without LEI. In the transitions with care need as the DESTINATION STATE (from Healthy to Care, or from Dementia to Dementia $\mathcal{E}$ Care), women had a markedly larger agespecific probability to experience these transitions than men. Regarding the transitions to the absorbing state death, men with LEI had the largest age-specific probability to die. In both sexes individuals with LEI always had a larger age-specific probability of dying than individuals without LEI.

For both sexes, the elderly with LEI spent generally shorter periods in each transient state than those without LEI (Table 3). At age 75, women who started healthy (initial state Healthy) but experienced LEI lost 2.10 years of rLE, males lost 1.97 years. More than $90 \%$ of the years lost were years free of dementia and independent of long-term care (women 2.00 years, males 1.79 years), while the years with dementia and care need were reduced only marginally. Women who started with dementia (initial state Dementia) lost 1.72 years of rLE, men lost 1.35 years. Again, the majority of YLL were years with dementia but free of care need (women: 1.05 years $=61 \%$; men: 0.93 years $=69 \%$ ). The same was true for those who started with care need but were free of dementia. The YLL (women: 0.56 years $=68 \%$; men 0.33 years $=69 \%$ ) were mainly years with physical limitations but intact cognitive functioning. For most transitions the YLL due to LEI were significantly different from zero at conventional significance levels. Furthermore, the elderly with LEI experienced more years with dementia and care as compared to years with dementia

Table 2 Hazard ratio of LEl for each transition

\begin{tabular}{llccc}
\hline Transition & & Hazard ratio & $95 \% \mathrm{Cl}$ of HR & $P$ \\
\hline 1 & 1 Healthy $->$ 2 Dementia & 1.54 & $1.46-1.62$ & $1.63-1.77$ \\
2 & 1 Healthy $->$ 3 Care & 1.70 & $1.16-1.33$ & $<0.001$ \\
3 & 1 Healthy - > 5 Dead & 1.24 & $1.39-1.54$ & $<0.001$ \\
4 & 2 Dementia - > 4 Dementia \& Care & 1.46 & $1.33-1.69$ & $<0.001$ \\
5 & 2 Dementia - > 5 Dead & 1.50 & $1.19-1.33$ & $<0.001$ \\
6 & 3 Care - > 4 Dementia \& Care & 1.26 & $1.10-1.22$ & $<0.001$ \\
7 & 3 Care - > 5 Dead & 1.16 & $1.23-1.33$ & $<0.001$ \\
8 & 4 Dementia \& Care - > 5 Dead & 1.28 & & $<0.001$ \\
\hline
\end{tabular}




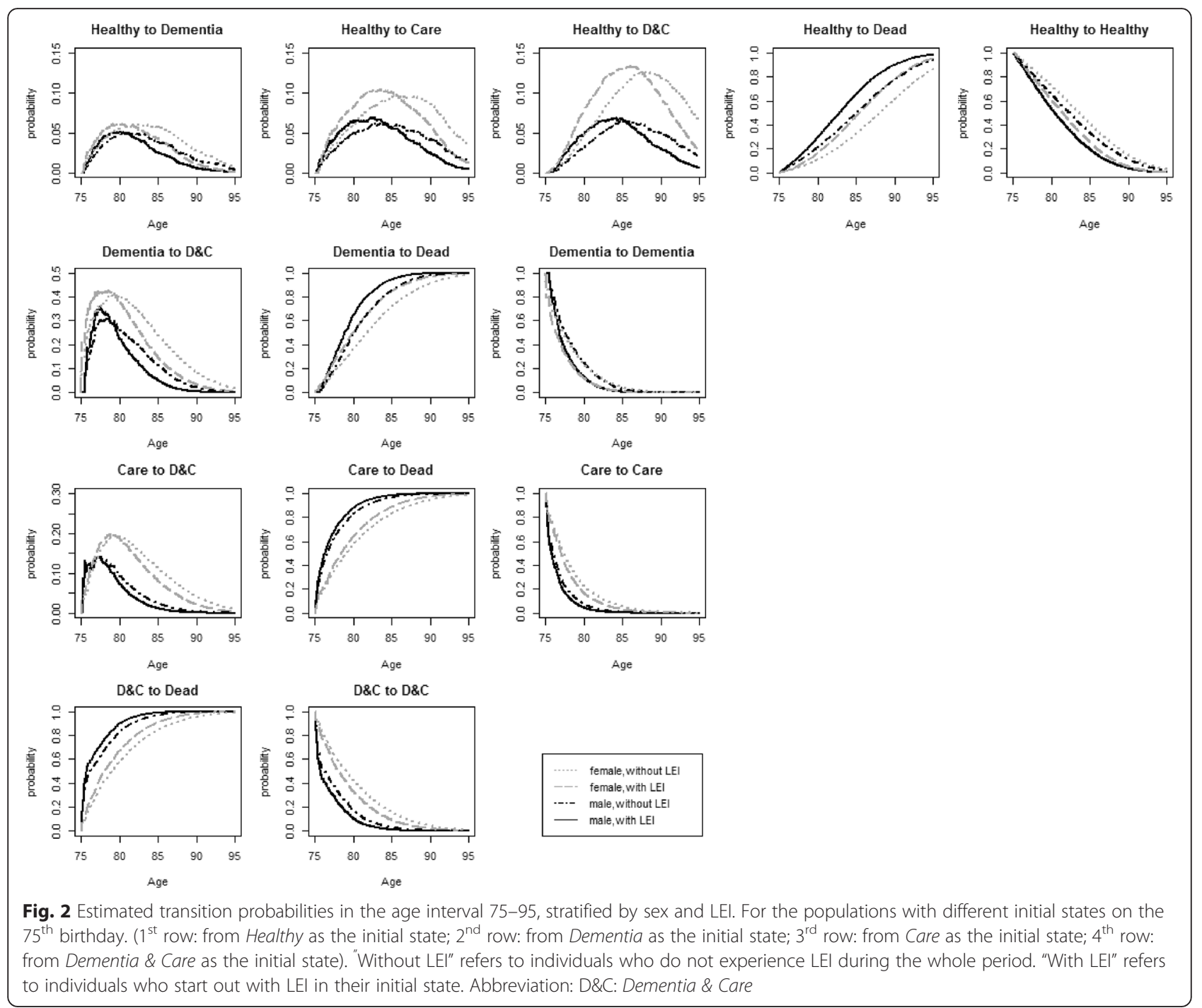

alone. Taking a 75-year-old healthy woman as an example, under the exposure of no-LEI her rLE in the state Dementia \& Care was 1.56 years, and 0.77 in the state Dementia which is a ratio of 2.03. For her counterpart with LEI, in contrast, the ratio is 2.53 (rLE 1.62 years Dementia \& Care: rLE 0.64 years Dementia). A similar ratio existed for men, and for Dementia as the initial state.

\section{Discussion}

Exploring individual transitions in a large populationbased data set, we found that LEI in the elderly significantly increased the risk of the entire adverse chain from health over dementia and care need to death and resulted in a large loss of years of life. Similarly important, we found that these lost years were mainly years with better health and fewer limitations, independently of whether the individual was initially healthy or suffered from dementia or was in need of care. LEI increased all age-specific death probabilities (particularly in men), and shifted the age-peak of the probabilities of the transient transitions forward (particularly the transitions to care need in women). LEI was generally associated with shortened life expectancy, but with relatively expanded life time with dementia and care need.

To our knowledge, this is the first study to explore the effect of LEI on the risk of dementia, care need, and death simultaneously in a multi-state model. Earlier studies primarily looked at separate endpoints at the individual level and did not derive compound measures at the population level, such as life expectancy and years of life lost. Our findings provide insight into the effects of LEI on both the functional outcomes (dementia, care need) and the survival outcomes holistically, which is highly recommended in the research fields of successful aging [35].

Furthermore, we studied LEI instead of only hip fractures or fall-induced fractures, because they are not as 
Table 3 Remaining life expectancy at age 75 (rLE) and $95 \%$ confidence intervals by initial state, stratified by sex and LEI

\begin{tabular}{|c|c|c|c|c|}
\hline Initial state & Destination state & rLE without LEI ${ }^{a}$ & rLE with LEl ${ }^{a}$ & YLL due to $\left.L E\right|^{b}$ \\
\hline \multicolumn{5}{|l|}{ Females } \\
\hline \multirow[t]{9}{*}{ 1. Healthy } & 1. Healthy & 8.95 & 6.95 & 2.00 \\
\hline & & (8.83 9.06) & $(6.797 .13)$ & $(1.842 .13)$ \\
\hline & 2. Dementia & 0.77 & 0.64 & 0.13 \\
\hline & & $(0.740 .81)$ & (0.59 0.68) & (0.09 0.18) \\
\hline & 3. Care & 1.33 & 1.30 & 0.03 \\
\hline & & (1.29 1.38) & $(1.241 .37)$ & $(-0.030 .09)$ \\
\hline & 4. Dementia \& Care & 1.56 & 1.62 & -0.06 \\
\hline & & $(1.521 .61)$ & $(1.561 .70)$ & $(-0.130 .01)$ \\
\hline & Total & 12.61 & 10.51 & 2.10 \\
\hline \multirow[t]{5}{*}{ 2. Dementia } & 2. Dementia & 3.19 & 2.14 & 1.05 \\
\hline & & $(1.954 .01)$ & (0.82 2.98) & $(0.901 .23)$ \\
\hline & 4. Dementia \& Care & 4.31 & 3.64 & 0.67 \\
\hline & & (3.97 4.59) & (3.20 3.94) & (0.49 0.90) \\
\hline & Total & 7.50 & 5.78 & 1.72 \\
\hline \multirow[t]{5}{*}{ 3. Care } & 3. Care & 3.40 & 2.84 & 0.56 \\
\hline & & (2.86 3.89) & (2.31 3.33) & 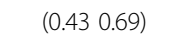 \\
\hline & 4. Dementia \& Care & 1.96 & 1.70 & 0.26 \\
\hline & & (1.63 2.38) & (1.38 2.12) & $(0.160 .37)$ \\
\hline & Total & 5.36 & 4.54 & 0.82 \\
\hline \multirow[t]{2}{*}{ 4. Dementia \& Care } & 4. Dementia \& Care & 5.24 & 4.21 & 1.03 \\
\hline & & (4.23 5.99) & (3.15 4.99) & $(0.861 .20)$ \\
\hline \multicolumn{5}{|l|}{ Males } \\
\hline \multirow[t]{9}{*}{ 1. Healthy } & 1. Healthy & 7.96 & 6.17 & 1.79 \\
\hline & & (7.81 8.12) & $(5.966 .38)$ & $\left(\begin{array}{ll}1.63 & 1.94\end{array}\right)$ \\
\hline & 2. Dementia & 0.57 & 0.46 & 0.11 \\
\hline & & $(0.530 .60)$ & $(0.420 .51)$ & $(0.070 .14)$ \\
\hline & 3. Care & 0.82 & 0.79 & 0.03 \\
\hline & & (0.79 0.87) & $(0.740 .85)$ & $\left(\begin{array}{lll}-0.01 & 0.08)\end{array}\right.$ \\
\hline & 4. Dementia \& Care & 0.79 & 0.75 & 0.04 \\
\hline & & $(0.750 .83)$ & $(0.700 .81)$ & $\left(\begin{array}{lll}-0.01 & 0.07)\end{array}\right.$ \\
\hline & Total & 10.14 & 8.17 & 1.97 \\
\hline \multirow[t]{5}{*}{ 2. Dementia } & 2. Dementia & 3.44 & 2.51 & 0.93 \\
\hline & & (3.01 3.92) & (2.08 2.95) & (0.79 1.07) \\
\hline & 4. Dementia \& Care & 2.42 & 2.00 & 0.42 \\
\hline & & $(2.202 .65)$ & $(1.772 .24)$ & $\left(\begin{array}{lll}0.31 & 0.52\end{array}\right)$ \\
\hline & Total & 5.86 & 4.51 & 1.35 \\
\hline \multirow[t]{5}{*}{ 3. Care } & 3. Care & 1.74 & 1.41 & 0.33 \\
\hline & & (1.30 2.18) & (0.99 1.82) & $\left(\begin{array}{lll}0.24 & 0.42)\end{array}\right.$ \\
\hline & 4. Dementia \& Care & 0.91 & 0.76 & 0.15 \\
\hline & & $(0.611 .25)$ & $(0.481 .07)$ & $\left(\begin{array}{lll}0.09 & 0.24)\end{array}\right.$ \\
\hline & Total & 2.65 & 2.17 & 0.48 \\
\hline \multirow[t]{2}{*}{ 4. Dementia \& Care } & 4. Dementia \& Care & 2.52 & 1.86 & 0.66 \\
\hline & & (1.72 3.34) & $(1.132 .62)$ & $(0.861 .20)$ \\
\hline
\end{tabular}


fatal but are still associated with worse disability outcomes and long-term care need [7, 28] and result in enormous societal costs [1]. In addition, given the large number of underreported falls [46], LEI is easier to notice for a doctor, a caregiver or a family member.

Our results not only confirm findings in previous studies, but also deepen the knowledge about the association between LEI and dementia, care need and death. We shall now discuss them briefly.

\section{LEI and care need}

We show that LEI increases the risk of care need, both among healthy elderly and among dementia patients. It is well known that fracture or fall-induced injuries in elderly are associated with poor functional outcomes and high burden of care, including longer stay in hospital and higher likelihood of long-term care facility $[7,13]$. The presence of dementia aggravates these negative effects [47]. The underlying mechanisms might be that LEI speeds up the course of dementia [48], or that dementia slows down functional recovery after LEI, thus increasing care need in patients with dementia [34, 49].

In our study, women generally have a higher probability of experiencing the transition to long-term care than men, despite their higher rLE, thus, supporting the outcome of earlier studies [50, 51]; LEI shifts their age at the transition even further forward.

\section{LEI and dementia}

We show that LEI is a risk factor or a predictor of dementia for both healthy individuals and for those with care need. Various mechanisms may explain the association between LEI and dementia. First, LEI in the elderly increases the risk of cognitive impairment, including delirium and depression $[16,20]$, which raises the risk of dementia onset [21, 52-54], and makes dementia worse and more progressive [55, 56]. Second, LEI restricts physical activity, mobility and social participation, at least during some periods of time $[9,10]$, thus restricting these potential preventive factors of dementia [22, 23]. The decreased mobility in long-term care residents, in particular, is associated with various psychosocial impairments such as depression and feeling of isolation [57]. Also, falls and the consequent fear of falling might lead to activity restriction in the long run [58, 59]. Third, there exist shared risk factors for LEI and dementia such as age, ApoE4, diabetes and vascular dysfunction, executive dysfunction and gait disturbances $[15,33]$.

Yet the observed association must be interpreted with caution because of the possibility of reversed causality. Although we have already taken temporality into account by only using LEI which occurred prior to or simultaneous with transitions as the exposure of interest, LEI can be regarded as a pre-symptom or an early symptom of undiagnosed dementia. Patients experiencing LEI may have already suffered from mild cognitive impairment or undiagnosed moderate dementia. Particularly, gait and balance disorders are common in NonAlzheimer's Dementia [60]. Moreover, delirium and depression may be two of the key intermediate factors between dementia and LEI, but the causal association between these and dementia is still controversial [54].

We find that women have a higher probability of developing dementia once they are in need of care, while both sexes have similar probabilities when they are healthy. This might explain why community dwelling cohort studies have not usually found significant sexdifferences in the age-specific incidence of dementia [61], while studies including the institutionalized population do find higher female dementia incidence [41].

\section{LEI and mortality}

We find that LEI generally increased the risk of death, and particularly did so among dementia patients. Higher mortality has been observed in several previous studies on fractures or falls $[8,10,25-28]$. Yet the underlying mechanism is still unclear. Some studies suggested that merely the event of the fracture and post fracture conditions related to trauma, instead of pre-existing comorbidities, is mainly responsible for the excess mortality $[8,62]$, whereas others claimed that the underlying health or comorbidities are linked to a large part of fracture-mortality association [63]. In line with our results, several previous studies have also pointed out that dementia is an independent risk factor or a predictor for mortality after fractures $[10,25,26,30]$.

Regardless of the initial state, men always had larger death probabilities, and LEI made this even worse by further increasing age-specific death probabilities and moving the age of death forward. Consistently, many studies on fractures or falls in elderly have reported that males are at an increased risk for death after LEI [8, 26-28].

\section{Strengths and limitations of our study}

In addition to the abovementioned strengths about the composite measure (YLL) and the holistic analysis (multistate model), our study has several further strengths. First, we use a large population-based sample of community dwelling and institutionalized elderly, avoiding bias due to sample selection and granting high statistical power. Second, we include a 6-year follow-up period, which permits us to analyze multiple transitions between different states and to explore the long-term effect of LEI with high statistical power. Finally, in comparison to self-reported or interview data, claims data is relatively objective, and free of recall bias or interview bias. 
Our study also has several limitations. First, the dementia in our cases was defined by a doctor's ICD diagnosis, which is prone to imperfect sensitivity and specificity. While we used an internal validation procedure to minimize the probability of false positive dementia diagnoses, we cannot account for underreporting. Second, in our data dementia may have already existed ahead of LEI, and LEI simply brought the dementia to clinical attention. Therefore, we interpreted the association observed between LEI and dementia with caution, particularly taking reverse causality into account. More research is needed to understand the interactions between cognitive and mobility decline [33], and other underlying mechanisms of the observed association between LEI and dementia.

Third, to evaluate the long-term effect, we defined LEI as an ever-variable, although some LEI may be apparently or actually cured. However, LEI can influence a patient in the long-term, even after recovery. A relationship has been found linking fall and subsequently fearrelated avoidance of activity [58]. Fourth, we discussed our results in comparison with quite a few previous literature on hip fractures or falls, which might be not directly comparable. However, the hip fracture (S72) in our data is the most frequent among the first 3-digits subgroups of the ICDs chosen. Fall-induced injuries in older adults account for the majority of geriatric injuries and their related hospital admissions [3, 64]. Fifth, we have no information about other potential confounders such as education, family status, or life style factors such as smoking, obesity, or alcohol consumption. Our multistate model also does not control for polypharmacy or multimorbidity. However, in sensitivity analyses of our hazard models we further controlled for the Charlsonmorbidity-index, brain injuries, osteoporosis, depression, Parkinson and Down-Syndrom at baseline, which did not alter our findings (not shown).

Moreover, given the crude nature of the quarterlybased data, we had to make assumption on the order in which LEI, dementia, care need and death occurred, in case more than one event happened within one quarter. Sensitivity analysis changing these orders still found a significantly increased risk of LEI for most transitions, albeit of smaller effect sizes (not shown).

\section{Conclusion}

Our study suggests that prevention and timely treatment of LEI as well as rehabilitative care after LEI may be of utmost importance in delaying or reducing the onset of care need and death, not only among cognitive intact elderly but also among dementia patients. These measures will not only help to save years of life, but also to increase the quality of life of the elderly and reduce the burden for families, public health, and the care system. Expressing the detrimental effect of LEI in terms of the composite measure YLL should prove helpful for the elderly, their families, and health professionals to holistically appreciate the scale of the problem and the substantial benefits of preventive and rehabilitative measures.

\section{Additional files}

Additional file 1: Table S1. ICDs used to identify dementia and lower extremity injury (ICD- 2010-GM). To list the concrete ICDs, which we used to identify dementia and lower extremity injury in our study. (DOCX $15 \mathrm{~kb}$ )

Additional file 2: Table S2. Numbers and percentages of transitions and exposure of interest (LEI) by age. Differentiates Table 1 which is included in the main document by 5-year age groups. (DOCX $19 \mathrm{~kb}$ )

\section{Abbreviations}

ADL: activities of daily living; BADL: basic activities of daily living;

Cl: confidence interval; Col: column; HR: hazard ratio; ICD: International Statistical Classification of Diseases and Related Health Problems; LEl: lower extremity injury; rLE: remaining life expectancy; SD: standard deviation; WIdO: Wissenschaftliches Institut der Ortskrankenkassen; YLL: years of life lost.

\section{Competing interests}

None of the authors declared a conflict of interest.

\section{Authors' contributions}

$Y Z$ performed the statistical analysis and wrote the first version of the paper. GD planned the study, supervised the data analysis, and contributed to writing the paper. HP contributed to statistical analysis. All authors revised the manuscript, and read and approved the final version.

\section{Acknowledgements}

We thank Anne Fink, Alexander Barth, and Anja Vatterrott who helped in handling the data, and provided advice in the statistical analysis. We are grateful to the scientific research institute of the AOK, WIdO, for providing the data. We thank the two anonymous referees for their comments which have led to substantial improvements of the article and Renee FlibotteLüskow for her English editing service.

Funding

This work was supported by the German Federal Ministry of Education and Research (16SV6373).

\section{Author details}

${ }^{1}$ Institute for Sociology and Demography, University of Rostock, Ulmenstrasse 69, 18057 Rostock, Germany. ${ }^{2}$ Rostock Center for the Study of Demographic Change, Konrad-Zuse-Str. 1, 18057 Rostock, Germany. ${ }^{3}$ Department of Medical Statistics and Bioinformatics, Leiden University Medical Centre, Einthovenweg 20, 2333 ZC Leiden, Netherlands. ${ }^{4}$ German Center for Neurodegenerative Disease, Ludwig-Erhard-Allee 2, 53175 Bonn, Germany.

Received: 26 February 2015 Accepted: 4 January 2016

Published online: 12 January 2016

References

1. Prince MJ, Wu F, Guo Y, Robledo G, Luis M, O'Donnell M, et al. The burden of disease in older people and implications for health policy and practice. Lancet. 2015;385:549-62. doi:10.1016/S0140-6736(14)61347-7.

2. Hashmi A, Ibrahim-Zada I, Rhee P, Aziz H, Fain MJ, Friese RS, et al. Predictors of mortality in geriatric trauma patients: a systematic review and metaanalysis. J Trauma Acute Care Surg. 2014;76:894-901. doi:10.1097/TA. Ob013e3182ab0763.

3. Aschkenasy MT, Rothenhaus TC. Trauma and falls in the elderly. Emerg Med Clin North Am. 2006;24:413-32. doi:10.1016/j.emc.2006.01.005. 
4. Marti GP, Liu L, Zhang X, Xing D, King DC, Kohli AR, et al. Wound healing in the elderly. In: Rosenthal RA, Zenilman ME, Katlic MR, editors. Principles and practice of geriatric surgery. New York: Springer; 2011. p. 107-27.

5. Moore L, Turgeon AF, Sirois M, Lavoie A. Trauma centre outcome performance: A comparison of young adults and geriatric patients in an inclusive trauma system. Injury. 2012;43:1580-5. doi:10.1016/j.injury. 2011.02.010

6. Breusch S, Mau H, Sabo D, Clarius M. Klinikleitfaden Orthopädie Unfallchirurgie. München: Elsevier; 2009.

7. Gill TM, Murphy TE, Gahbauer EA, Allore HG. Association of injurious falls with disability outcomes and nursing home admissions in community-living older persons. Am J Epidemiol. 2013;178:418-25. doi:10.1093/aje/kws554.

8. Bliuc D. Mortality risk associated with low-trauma osteoporotic fracture and subsequent fracture in men and women. JAMA. 2009;301:513. doi:10.1001/ jama.2009.50

9. Lo AX, Brown CJ, Sawyer P, Kennedy RE, Allman RM. Life-space mobility declines associated with incident falls and fractures. J Am Geriatr Soc. 2014; 62:919-23. doi:10.1111/jgs.12787.

10. Bentler SE, Liu L, Obrizan M, Cook EA, Wright KB, Geweke JF, et al. The aftermath of hip fracture: discharge placement, functional status change, and mortality. Am J Epidemiol. 2009;170:1290-9. doi:10.1093/aje/kwp266.

11. González-Zabaleta J, Pita-Fernandez S, Seoane-Pillado T, López-Calviño B, Gonzalez-Zabaleta JL. Dependence for basic and instrumental activities of daily living after hip fractures. Arch Gerontol Geriatr. 2015;60:66-70. doi:10.1016/j.archger.2014.10.020.

12. Rubenstein LZ. Falls in older people: epidemiology, risk factors and strategies for prevention. Age Ageing. 2006;35:ii37-41. doi:10.1093/ageing/afl084.

13. Dunne TJ, Gaboury I, Ashe MC. Falls in hospital increase length of stay regardless of degree of harm. J Eval Clin Pract. 2014;20:396-400. doi:10.1111/jep.12144

14. Gruber-Baldini AL, Zimmerman S, Morrison RS, Grattan LM, Hebel JR, Dolan $M M$, et al. Cognitive impairment in hip fracture patients: timing of detection and longitudinal follow-up. J Am Geriatr Soc. 2003;51:1227-36. doi:10.1046/j. 1532-5415.2003.51406.x.

15. Friedman SM, Menzies IB, Bukata SV, Mendelson DA, Kates SL. Dementia and hip fractures: development of a pathogenic framework for understanding and studying risk. Geriatr Orthop Surg Rehabil. 2010;1:52-62. doi:10.1177/2151458510389463.

16. Krogseth M, Wyller TB, Engedal $K$, Juliebø V. Delirium is an important predictor of incident dementia among elderly hip fracture patients. Dement Geriatr Cogn Disord. 2011;31:63-70. doi:10.1159/000322591.

17. Bauer K, Schwarzkopf L, Graessel E, Holle R. A claims data-based comparison of comorbidity in individuals with and without dementia. BMC Geriatr. 2014; 14:10. doi:10.1186/1471-2318-14-10

18. van Doorn C, Gruber-Baldini AL, Zimmerman S, Richard Hebel J, Port CL, Baumgarten $\mathrm{M}$, et al. Dementia as a risk factor for falls and fall injuries among nursing home residents. J Am Geriatr Soc. 2003;51:1213-8. doi:10.1046/j.1532-5415.2003.51404.x.

19. Wesson J, Clemson L, Brodaty H, Lord S, Taylor M, Gitlin L, et al. A feasibility study and pilot randomised trial of a tailored prevention program to reduce falls in older people with mild dementia. BMC Geriatr. 2013;13:89. doi:10.1186/1471-2318-13-89.

20. Matheny ME, Miller RR, Shardell MD, Hawkes WG, Lenze EJ, Magaziner J, et al. Inflammatory cytokine levels and depressive symptoms in older women in the year after hip fracture: findings from the Baltimore hip studies. J Am Geriatr Soc. 2011;59:2249-55. doi:10.1111/j.1532-5415.2011.03727.x.

21. Davis DHJ, Terrera GM, Keage H, Rahkonen T, Oinas M, Matthews FE, et al. Delirium is a strong risk factor for dementia in the oldest-old: a populationbased cohort study. Brain. 2012;135:2809-16. doi:10.1093/brain/aws190.

22. Wang $H$, Karp A, Winblad B, Fratiglioni L. Late-life engagement in social and leisure activities is associated with a decreased risk of dementia: a longitudinal study from the kungsholmen project. Am J Epidemiol. 2002; 155:1081-7. doi:10.1093/aje/155.12.1081

23. Norton S, Matthews FE, Barnes DE, Yaffe K, Brayne C. Potential for primary prevention of Alzheimer's disease: an analysis of populationbased data. Lancet Neurol. 2014;13:788-94. doi:10.1016/S14744422(14)70136-X.

24. Wyller TB, Watne LO, Torbergsen A, Engedal K, Frihagen F, Juliebo V, et al The effect of a pre- and post-operative orthogeriatric service on cognitive function in patients with hip fracture. The protocol of the Oslo Orthogeriatrics trial. BMC Geriatr. 2012;12:36. doi:10.1186/1471-2318-12-36.
25. Hershkovitz A, Polatov I, Beloosesky Y, Brill S. Factors affecting mortality of frail hip-fractured elderly patients. Arch Gerontol Geriatr. 2010;51:113-6. doi:10.1016/j.archger.2009.09.003.

26. Scandol JP, Toson B, Close JC. Fall-related hip fracture hospitalisations and the prevalence of dementia within older people in New South Wales, Australia: An analysis of linked data. Injury. 2013;44:776-83. doi:10.1016/j. injury.2012.11.023.

27. Neuman MD, Silber JH, Magaziner JS, Passarella MA, Mehta S, Werner RM. Survival and functional outcomes after hip fracture among nursing home residents. JAMA Intern Med. 2014;174:1273-80. doi:10.1001/jamainternmed.2014.2362

28. Center JR, Nguyen TV, Schneider D, Sambrook PN, Eisman JA. Mortality after all major types of osteoporotic fracture in men and women: an observational study. Lancet. 1999;353:878-82. doi:10.1016/S01406736(98)09075-8.

29. Grønskag AB, Romundstad P, Forsmo S, Langhammer A, Schei B. Excess mortality after hip fracture among elderly women in Norway. Osteoporos Int. 2012;23:1807-11. doi:10.1007/s00198-011-1811-y.

30. Baker NL, Cook MN, Arrighi HM, Bullock R. Hip fracture risk and subsequent mortality among Alzheimer's disease patients in the United Kingdom, 1988-2007. Age Ageing. 2011;40:49-54. doi:10.1093/ageing/afq146.

31. Castronuovo E, Pezzotti P, Franzo A, Di Lallo D, Guasticchi G. Early and late mortality in elderly patients after hip fracture: a cohort study using administrative health databases in the Lazio region, Italy. BMC Geriatr. 2011;11:37. doi:10.1186/1471-2318-11-37.

32. Seitz DP, Anderson GM, Austin PC, Gruneir A, Gill SS, Bell CM, et al. Effects of impairment in activities of daily living on predicting mortality following hip fracture surgery in studies using administrative healthcare databases. BMC Geriatr. 2014;14:9. doi:10.1186/1471-2318-14-9.

33. Montero-Odasso $M$, Hachinski V. Preludes to brain failure: executive dysfunction and gait disturbances. Neurol Sci. 2014;35:601-4. doi:10.1007/ s10072-013-1613-4.

34. Inagawa T, Hamagishi T, Takaso Y, Hitomi Y, Kambayashi Y, Hibino Y, et al. Decreased activity of daily living produced by the combination of Alzheimer's disease and lower limb fracture in elderly requiring nursing care. Environ Health Prev Med. 2013;18:16-23. doi:10.1007/ s12199-012-0283-9.

35. Nusselder WJ, Peeters A. Successful aging: measuring the years lived with functional loss. J Epidemiol Community Health. 2006;60:448-55. doi:10.1136/jech.2005.041558.

36. Hannan EL, Magaziner J, Wang JJ, Eastwood EA, Silberzweig SB, Gilbert M, et al. Mortality and locomotion 6 months after hospitalization for hip fracture. JAMA. 2001:285:2736-42. doi:10.1001/jama.285.21.2736.

37. Putter $H$, Hage $v d$, Jos d B, Geertruida $H$, Elgalta R, Velde $v$ d, et al. Estimation and prediction in a multi-state model for breast cancer. Biom J. 2006:48:366-80. doi:10.1002/bimj.200510218

38. Houwelingen v, Anne H, Cameron ID, Gussekloo J, Putter H, Kurrle S, et al. Disability transitions in the oldest old in the general population. The Leiden 85-plus study. AGE. 2014;36:483-93. doi:10.1007/s11357-013-9574-3.

39. van Houwelingen $\mathrm{HC}$, Putter H. Dynamic predicting by landmarking as an alternative for multi-state modeling: an application to acute lymphoid leukemia data. Lifetime Data Anal. 2008;14:447-63. doi:10.1007/s10985-008-9099-8.

40. Peeters A. A cardiovascular life history. Eur Heart J. 2002;23:458-66. doi:10.1053/euhj.2001.2838.

41. Doblhammer G, Schulz A, Steinberg J, Ziegler U. Demografie der Demenz. Bern: Hans Huber; 2012

42. Becker C, Leistner K, Nikolaus T. Introducing a statutory insurance system for long-term care (Pflegeversicherung) in Germany. In: Michel JP, Rubenstein LZ, Vellas BJ, Albarede JL, editors. Geriatric programs and departments around the world. Paris-New York: Serd-Springer; 1998. p. 55-64.

43. Putter H, Fiocco M, Geskus RB. Tutorial in biostatistics: competing risks and multi-state models. Statist Med. 2007;26:2389-430. doi:10.1002/sim.2712.

44. De Wreede LC, Fiocco M, Putter H. mstate: An R package for the analysis of competing risks and multi-state models. J Stat Softw. 2011;38:1-30. doi:10. 18637/jss.v038.i07.

45. Datta S, Satten GA. Validity of the Aalen-Johansen estimators of stage occupation probabilities and Nelson-Aalen estimators of integrated transition hazards for non-Markov models. Stat Probability Lett. 2001;55: 403-11. doi:10.1016/S0167-7152(01)00155-9.

46. Shumway-Cook A, Ciol MA, Hoffman J, Dudgeon BJ, Yorkston K, Chan L. Falls in the medicare population: incidence, associated factors, and impact on health care. Phys Ther. 2009;89:324-32. doi:10.2522/ptj.20070107. 
47. Afram B, Verbeek H, Bleijlevens MH, Challis D, Leino-Kilpi H, Karlsson S, et al. Predicting institutional long-term care admission in dementia: a mixedmethods study of informal caregivers' reports. J Adv Nurs. 2014. doi:10.1111/jan.12479.

48. Arrighi HM, Neumann PJ, Lieberburg IM, Townsend RJ. Lethality of Alzheimer disease and its impact on nursing home placement. Alzheimer Dis Assoc Disord. 2010;24:90-5. doi:10.1097/WAD.0b013e31819fe7d1.

49. Givens JL, Sanft TB, Marcantonio ER. Functional recovery after hip fracture: the combined effects of depressive symptoms, cognitive impairment, and delirium. J Am Geriatr Soc. 2008;56:1075-9. doi:10.1111/j.1532-5415. 2008.01711.x.

50. Martikainen P, Moustgaard H, Einiö E, Murphy M. Life expectancy in longterm institutional care by marital status: multistate life table estimates for older finnish men and women. J Gerontol Ser B Psychol Sci Soc Sci. 2014; 69:303-10. doi:10.1093/geronb/gbt131.

51. Seshadri S, Wolf PA. Lifetime risk of stroke and dementia: current concepts, and estimates from the Framingham Study. Lancet Neurol. 2007;6:1 106-14. doi:10.1016/S1474-4422(07)70291-0.

52. Bennett S, Thomas AJ. Depression and dementia: cause, consequence or coincidence? Maturitas. 2014;79:184-90. doi:10.1016/j.maturitas.2014.05.009.

53. Lundström M, Edlund A, Bucht $G$, Karlsson S, Gustafson Y. Dementia after delirium in patients with femoral neck fractures. J Am Geriatr Soc. 2003:51: 1002-6. doi:10.1046/j.1365-2389.2003.51315.x.

54. Inouye SK, Westendorp RGJ, Saczynski JS. Delirium in elderly people. Lancet. 2014;383:911-22. doi:10.1016/S0140-6736(13)60688-1.

55. Fong TG, Jones RN, Shi P, Marcantonio ER, Yap L, Rudolph JL, et al. Delirium accelerates cognitive decline in Alzheimer disease. Neurology. 2009;72: 1570-5. doi:10.1212/WNL.0b013e3181a4129a.

56. Rapp K. People with Alzheimer's disease are at increased risk of hip fracture and of mortality after hip fracture. Evid Based Nurs. 2011;14:78-9. doi:10.1136/ebn1160.

57. Dal B-H, Vanina PM, Thorpe LU, Lix LM, Scudds R, Hadjistavropoulos T. The effects of a long-term care walking program on balance, falls and well-being. BMC Geriatr. 2012;12:76. doi:10.1186/1471-2318-12-76.

58. Delbaere K, Crombez G, Vanderstraeten G, Willems T, Cambier D. Fear-related avoidance of activities, falls and physical frailty. A prospective community-based cohort study. Age Ageing. 2004;33:368-73. doi:10.1093/ ageing/afh 106

59. Nyman SR, Ballinger C, Phillips JE, Newton R. Characteristics of outdoor falls among older people: a qualitative study. BMC Geriatr. 2013;13:125. doi:10.1186/1471-2318-13-125.

60. Allan LM, Ballard CG, Burn DJ, Kenny RA. Prevalence and severity of gait disorders in Alzheimer's and Non-Alzheimer's dementias. J Am Geriatr Soc. 2005:53:1681-7. doi:10.1111/j.1532-5415.2005.53552.x

61. Alzheimer's Association. 2014 Alzheimer's Disease Facts and Figures. 2014. http://www.alz.org/downloads/facts_figures_2014.pdf. Accessed 10 Oct 2015

62. Vestergaard P, Rejnmark L, Mosekilde L. Increased mortality in patients with a hip fracture-effect of pre-morbid conditions and post-fracture complications. Osteoporos Int. 2007;18:1583-93. doi:10.1007/s00198-007-0403-3.

63. Tosteson ANA, Gottlieb DJ, Radley DC, Fisher ES, Melton LJ. Excess mortality following hip fracture: the role of underlying health status. Osteoporos Int. 2007;18:1463-72. doi:10.1007/s00198-007-0429-6.

64. Kannus $P$, Sievänen $H$, Palvanen $M$, Järvinen $T$, Parkkari J. Prevention of falls and consequent injuries in elderly people. Lancet. 2005;366:1885-93. doi:10.1016/S0140-6736(05)67604-0.

\section{Submit your next manuscript to BioMed Central and we will help you at every step:}

- We accept pre-submission inquiries

- Our selector tool helps you to find the most relevant journal

- We provide round the clock customer support

- Convenient online submission

- Thorough peer review

- Inclusion in PubMed and all major indexing services

- Maximum visibility for your research

Submit your manuscript at www.biomedcentral.com/submit

) Biomed Central 